\title{
Evaluation of Neurodevelopment and Factors Affecting it in Children With Acyanotic Congenital Cardiac Disease
}

\author{
Ayten Ozmen, Semiha Terlemez,, ${ }^{2, *}$ Fatma Sedef Tunaoglu, ${ }^{2}$ Sebnem Soysal, ${ }^{1}$ Ayhan Pektas, ${ }^{2}$ \\ Erman Cilsal, ${ }^{2}$ Ulker Koca, ${ }^{3}$ Serdar Kula, ${ }^{2}$ and Ayse Deniz Oguz ${ }^{2}$ \\ ${ }_{1}^{1}$ Department of Pediatrics, Faculty of Medicine, Gazi University, Ankara, Turkey \\ ${ }_{3}^{2}$ Pediatric Cardiology Department, Faculty of Medicine, Gazi University, Ankara, Turkey \\ ${ }^{3}$ Pediatric Hematology Department, Faculty of Medicine Gazi University, Ankara, Turkey \\ ${ }^{*}$ Corresponding author: Semiha Terlemez, Pediatric Cardiology Department, Faculty of Medicine, Gazi University, Ankara, Turkey. Tel: +90-5327217689, Fax: +90-2562562573, \\ E-mail: semihaterlemez@yahoo.com \\ Received 2015 June 29; Revised 2015 October 17; Accepted 2015 November 2.
}

\begin{abstract}
Background: The rate of congenital heart disease is $0.8 \%$ in all live births. The majority of this, however, is acyanotic congenital heart disease. The survival rate of children with cardiac disease has increased with the developments provided in recent years and their lifetime is extended.

Objectives: This study aims to evaluate neurodevelopment of children with uncomplicated acyanotic congenital heart disease in preschool period and determine the factors affecting their neurodevelopmental process.

Patients and Methods: 132 children with acyanotic congenital heart disease aged 6 - 72 months were involved in the study. Mental development and intelligence levels of patients under 2 years old were assessed by using Bayley Development Scale-III, and Stanford Binet Intelligence test was employed for patients over 2 years old. Denver Developmental Screening Test II was applied to all patients for their personal-social, fine motor, gross motor and language development.

Results: The average age of patients ( 67 girls, 65 boys) included in the study was $35.2 \pm 19.6$ months. It was determined that there were subnormal mental level in 13(10\%)patients and at least one specific developmental disorder in 33(25\%)patients. Bayley Mental Development Scale score of patients who had received incubator care in perinatal period was found significantly low $(88 \pm 4.2)$ compared to those with no incubator care $(93.17 \pm 8.5)(\mathrm{P}=0.028)$. Low educational level of father was established to be linked with low mental development scores at the age of 2 and following that age $(\mathrm{P}<0.05)$. Iron deficiency anemia was discovered to be related to low psychometric test scores at every age $(\mathrm{P}<0.05)$.

Conclusions: Neurodevelopmental problems in children with acyanotic congenital heart disease were found higher compared to those in society. Mental development and intelligence levels of patients were determined to be closely associated with receiving incubator care, father's educational level and iron deficiency anemia.
\end{abstract}

Keywords: Acyanotic Congenital Heart Disease, Psychometric Assessment, Mental Development

\section{Background}

The rate of congenital heart disease is $0.8 \%$ in all live births (1). The majority of this, however, is acyanotic congenital heart disease. The survival rate of children with cardiac disease has increased with the developments provided in recent years and their lifetime is extended. Therefore, it has gained priority to have similar characteristics with their healthy peers by raising the quality of life, and motor and mental development of these patients.

It is known that cerebral developmental problems are seen more common in children with congenital heart disease than in normal population $(2,3)$ and in addition, brain maturation is delayed (4). Periventricular leukomalacia has been determined at a quite high rate in mature-born children with congenital heart disease $(5,6)$. It has been shown that behavioral and neurological impairments develop in some of children with congenital heart disease and academic performances and intellectual functions remain behind compared to those of their healthy peers (7). Nevertheless, studies performed focused on the children with complex congenital heart disease. It has been established that if cardiac disease is more complex, neurodevelopmental impairments increase at that rate $(4,5)$. No neurodevelopmental evaluation of children with acyanotic congenital heart disease has been carried out yet.

Neurodevelopment of children with congenital heart disease is determined with genetic and environmental factors as in that of healthy children. Although genetic factors are unchangeable, environmental factors are changeable. Therefore, it is important that these factors are presented.

\section{Objectives}

In this study, it was aimed to evaluate mental, emotional, social and psychomotor development of children with

Copyright (C) 2016, Growth \& Development Research Center. This is an open-access article distributed under the terms of the Creative Commons Attribution-NonCommercial 4.0 International License (http://creativecommons.org/licenses/by-nc/4.0/) which permits copy and redistribute the material just in noncommercial usages, provided the original work is properly cited. 
Ozmen A et al.

acyanotic congenital heart disease in preschool period and factors affecting it.

\section{Patients and Methods}

132 patients aged 6 - 72 months and followed-up with acyanotic congenital heart disease (CCD) at Gazi University, Faculty of Medicine, Pediatric Cardiology Department, were evaluated.

Patients whose weight, height and head circumference percentiles were within normal limits; with no accompanying other chronic diseases and without any inherited mental and motor disease history were evaluated in the study. Patients' undergone cardiac surgical operation or those with heart failure and known genetic impairments were not included in the study to exclude genetic structural problems and issues based on operative factors and potential cerebral blood supply related to hypoxia and hypotension. Patients younger than 6 months old were not involved in the study due to application disorder of psychomotor tests. Healthy control group was not included in the study.

Since adverse effects of iron deficiency anemia were proved on neurocognitive functions, to evaluate anemia and iron deficiency conditions of patients; hemoglobin ( $\mathrm{Hb})$, hematocrit (Hct), mean corpuscular volume (MCV), mean corpuscular hemoglobin $(\mathrm{MCH})$, mean corpuscular hemoglobin concentration (MCHC), red blood cell distrubution width (RDW), iron, iron binding capacity (IBC), transferrin saturation (TS) and ferritin levels of all patients were assessed. Patients who had iron treatment in the last 3 months or had received blood transfusion were not included in the study.

Income level, birth history, breast milk intake, prenatal, natal and postnatal history at the first admission. Given the minimum subsistence conditions of the country, those with $<1000$ TL monthly income levels were considered as low income and those with $>3000$ TL were regarded as high income families. Written consent was obtained from families for the study.

\subsection{Neurodevelopmental Evaluation}

Denver developmental screening test II (DGTT II) was applied to all patients. Test and survey were carried out by a pediatrician with DGTT II certificate. Stanford Binet was performed to cases over two years old and Bayley Scales of Infant and Toddler Development III was applied to those at the age of two and under two to get developmental evaluation and scores. Development screening test and behavior scores were carried out by a psychologist unaware of the illness of cases in psychometry room.

Development Scale-III for Bayley Babies consists of scales completing each other to evaluate developmental conditions of children aged $2-30$ months old $(8,9)$. Evaluations are conducted in two different fields including mental development scale and movement development scale. The conditions for Bayley Mental Development Scale are as follow: <69: intellectual disability, 70 - 84: mean developmental delay (dull normal), 85 -114: normal, > 115: good developmental performance (bright normal).

Mental level of children aged over two years was measured by Stanford Binet intelligence test. The conditions for Stanford Binet are regarded as follow: 70 - 79 borderline mental retardation, 80 - 89 dull normal, 90 - 109 normal intelligence, 110 - 119 bright intelligence (10).

DGTT II consists of 116 items collected under four sections on the test form to overview developmental areas. This section accounts for 1 . Personal-social 2. Fine-motor 3. Language development and 4. Gross-motor development. While test results are evaluated, it is assessed as advanced if the child demonstrates skills eligible for older ages than his or hers; if they are proper for his/her age it is regarded as normal; if the child cannot exhibit skills proper for his/ her age and they are appropriate for those under his/her age, it is accepted as delay. If the child cannot demostrate skills eligible for older ages and refuses to carry out skills proper for his/her age, warning point is given to him/her $(11,12)$. The result of DGTT II is evaluated as below:

Normal development: There is no delay or at maximum one warning.

Abnormal development: There is one or more than one delay situation; the child is recommended to be sent to the center for diagnostic evaluation.

Suspicious development: It is a situation involving one delay, one delay and one warning or two or more than two warnings. The test is repeated three months later and if it is found suspicious again, it is sent for diagnostic evaluation.

The study was carried out by obtaining Dr. Zekai Tahir Burak Women's Health Training and Research Hospital Ethics Committee approval (approval date/number: 14.5.2013/15).

\subsection{The Analysis of Data}

Statistical evaluation was carried out with SPSS 16 (social package for social sciences) statistical computer program. When the number of cases was lower than 30, non-parametrical tests and median values were used. In the event variable was qualitative, comparisons were performed with chisquare test between groups. Non-parametrical Kruskal-Wallis test was carried out in comparison of median values of independent groups. When a statistically significant value was found, Mann-Whitney U test was used for further evaluation. Wilcoxon test was used for further evaluation in comparison of dependent group median values. Results were assessed in $95 \%$ confidence interval and at significance $\mathrm{P}<0.05$ level.

\section{Results}

The study comprises 132 patients with acyanotic congenital heart disease including 67 (50.8\%) females and 65 (49.2\%) males aged 6 - 72 (average $35.2 \pm 19.6$ ) months. The distribution of diagnoses showed atrial septal defect (ASD) 67 (50.8\%), ventricular septal defect(VSD) 34 (25.8\%), patent ductus arteriosus (PDA) 18 (13.6\%), aorta coarctation (AC) 8 (6\%), ASD+PDA 1 (0.75\%), VSD+PDA1(0.75\%), pulmonary stenosis (PS) 1(0.75\%) and aortic setenosis. 
Weight-height percentiles of all cases were between 3 - 97 . While the average age of mothers involved in the study was $29.6 \pm 5.5$ years that of fathers was $33.6 \pm 5.6$ years. $25(18.9 \%)$ cases were determined with kin marriage in their family history. The number of working mothers was 22 (16.7\%) and 2 of them (1.5\%) had never breastfed. Supplementary food was initiated on time in $85 \%$ of cases; hovewer, it was delayed in $15 \% .74$ (56\%) of the cases got formula support in any period of their nourrishment, 58 (43.9\%) were never breastfed. Survey results of patients' parents included in the study are shown in Table 1.

\subsection{The Evaluation Results of Stanford Binet and Bayley Mental Development Scale III}

The test results of Stanford Binet and Bayley Mental Development Scale III regarding all case groups are given in Table 2 . When psychometric test results were standardized by ignoring the age of patients, $84 \%$ of the case group was found in normal interval (Table 2).

The specific impairments seen in Stanford Binet and Bayley Baby Development Scale evaluations in cases are shown in Table 3. The conditions such as speech problem in five patients, attention deficit in four patients, hyperactivity disorder (DEHB) and learning disability in ten patients, and/or growth retardation and motor retardation in four patients were determined (Table 3 ).

No significant effect of conditions such as prematurity, sex, medicine use in pregnancy, smoking and present disease history, breast milk intake period and formula use was established in psychometric evaluation results of patients $(\mathrm{P}>0.05)$.

The cases under two years old with incubator care in birth got significantly lower points (median $88 \pm 4.2$ ) in Bayley Mental Development Scale evaluation than those without incubator care $(93.17 \pm 8.5)(\mathrm{P}=0.028)$. No significant effect associated with incubator care was observed in other psychometric evaluation results (Table 4).

The level of education of mothers did not constitute a significant difference on psychometric evaluation results $(P>0.05)$. A statistically significant difference was seen in terms of Bayley Mental Development Scale values between groups of father education level $(\mathrm{P}<0.05)$. Bayley mental developmental scale values were significantly lower in fathers with secondary school degree and those lower than that compared to those with high school degree. Stanford Binet test values were significantly lower in fathers with secondary school or under it degree compared to those with high school degree $(P=0.03)$ (Table 5).

The evaluation carried out by Binet development test revealed that the higher income led to a significant increase in median points $(\mathrm{P}=0.02)$. No significant relationship was determined in an evaluation conducted with Bayley mental and movement development scales for children under six between the income level of the family and development tests (Table 6). When psychometric data were examined according to monthly income levels and study groups, no statistically significant difference was identified.
According to hematologic characteristics of patients, their psychometric test results were compared. Ferritin levels under $12 \mu \mathrm{g} / \mathrm{dL}$ were defined as iron deficiency. Anemia, on the other hand, was determined as hemoglobin, hematocrit or erythrocyte values to be below 2 standard deviations of normal average values according to age and gender (13). Iron deficiency was seen in 74 (56\%) out of 132 patients and iron deficiency anemia was diagnosed in $21(15.9 \%)$ patients. Psychometric results of patients with and without anemia were compared. Psychometric test results of patients with anemia were found significantly low compared to those without anemia (Table 7).

\subsection{Denver Developmental Screening Test II Evaluation Results}

Evaluation in four areas including personal social development, language, fine and gross motor skills was performed with Denver Developmental Screening Test II. Effects such as gender, preterm birth history, incubator care, parents' level of education and monthly income level of family on Denver developmental test results were not determined $(\mathrm{P}>0.05)$ (Table 8).

\begin{tabular}{|c|c|}
\hline Variables & Number (\%) \\
\hline Intermarriage & $25(18.9)$ \\
\hline \multicolumn{2}{|l|}{ Education situation of families } \\
\hline Higher education in mother or father & $36(27.2)$ \\
\hline Lower education in mother or father & $47(35.6)$ \\
\hline \multicolumn{2}{|l|}{ Income level of family } \\
\hline Low income level & $17(12.8)$ \\
\hline Average income level & $97(73.4)$ \\
\hline High income level & $18(13.6)$ \\
\hline \multicolumn{2}{|l|}{ Birth weight } \\
\hline$<1000 \mathrm{gr}$ & $2(1.5)$ \\
\hline $1000-2000 \mathrm{gr}$ & $7(5.3)$ \\
\hline$>2000 \mathrm{gr}$ & $123(90.9)$ \\
\hline Preterm birth history & $30(22.7)$ \\
\hline The number of working mothers & $22(16.7)$ \\
\hline Smoking in pregnancy & $12(9)$ \\
\hline Alcohol use in pregnancy & $1(0.8)$ \\
\hline \multicolumn{2}{|l|}{ Drug use in pregnancy } \\
\hline L-thyroxin & $4(3)$ \\
\hline Antihypertensive & $2(1.5)$ \\
\hline \multicolumn{2}{|l|}{ Accompanying disease in pregnancy } \\
\hline Hypothyroidism & $4(3)$ \\
\hline Gestational diabetes & $2(1.5)$ \\
\hline Preeclampsia & $2(1.5)$ \\
\hline \multicolumn{2}{|l|}{ Breastmilk intake } \\
\hline Less than 6 months & $31(23.3)$ \\
\hline More than 6 months & $99(75)$ \\
\hline Initiation of supplementary food on time & $112(85)$ \\
\hline Previous intake history of iron prophylaxis & $26(19.7)$ \\
\hline
\end{tabular}


Ozmen A et al.

\begin{tabular}{lc}
\hline Table 2. Psychometric Test Evaluation Results of Patients & \\
\hline General Results & Number (\%) \\
\hline Borderline mental retardation & $3(2)$ \\
Dull normal & $10(8)$ \\
Normal & $111(84)$ \\
Bright normal & $8(6)$ \\
Total & $132(100)$ \\
\hline
\end{tabular}

\begin{tabular}{lc}
\hline Table 3. Specific Impairments Determined in Children With Acyanotic Congenital Heart Disease \\
\hline Specific Impairments & Number (\%) \\
\hline Unidentified specific problem & $99(75)$ \\
\hline Delay in speech & $7(5.4)$ \\
\hline ADHD & $4(3)$ \\
Slowness in fine movements & $5(3.8)$ \\
\hline Gross movement retardation & $3(2.3)$ \\
\hline Learning difficulty and development retardation & $10(7.5)$ \\
\hline Articulation impairment, utter inability specific sounds & $4(3)$ \\
\hline Total & $132(100)$ \\
\hline
\end{tabular}

Abbreviation: ADHD, attention deficit hyperactivity disorder.

\begin{tabular}{|c|c|c|c|c|c|c|}
\hline & \multirow[t]{2}{*}{ Incubation Care } & \multirow[t]{2}{*}{ No Incubation Care } & \multirow[t]{2}{*}{ Total } & \multicolumn{3}{|c|}{ Kruskal Wallis Test } \\
\hline & & & & Chi-Square & DF & $\mathbf{P}$ \\
\hline \multicolumn{7}{|c|}{ Bayley mental development scale } \\
\hline Number & 10 & 35 & 45 & 4.86 & 1 & .028 \\
\hline Median & $88 \pm 4.2$ & $93.17 \pm 8.5$ & $92.12 \pm 8$ & & & \\
\hline \multicolumn{7}{|c|}{ Bayley movement development scale } \\
\hline Number & 10 & 35 & 45 & 1.76 & 1 & .185 \\
\hline Median & $90.2 \pm 3.7$ & $93.61 \pm 9.6$ & $92.91 \pm 8.8$ & & & \\
\hline \multicolumn{7}{|c|}{ Stanford binet } \\
\hline Number & 20 & 67 & 87 & 1.2 & 1 & .73 \\
\hline Median & $97 \pm 11.6$ & $100.21 \pm 8.1$ & $99.44 \pm 9.1$ & & & \\
\hline
\end{tabular}

\begin{tabular}{|c|c|c|c|c|c|}
\hline \multirow[t]{2}{*}{ Father Education Level } & \multirow[t]{2}{*}{ Number } & \multirow[t]{2}{*}{ Average (Min-Max) } & \multicolumn{3}{|r|}{ Kruskal Wallis H Test } \\
\hline & & & Line & $\mathbf{H}$ & Primary High School Comparison $P$ \\
\hline \multicolumn{6}{|c|}{ Bayley mental development scale } \\
\hline Primary and secondary & 12 & $88.3 \pm 3.4(83-96)$ & 15.7 & 7.0 & .03 \\
\hline High school & 24 & $92.4 \pm 7.3(73-115)$ & 27.7 & NA & NA \\
\hline University and over & 9 & $95.5 \pm 11,7(82-119)$ & 28.9 & NA & NA \\
\hline Total & 45 & $92.1 \pm 8.1(73-119)$ & NA & NA & NA \\
\hline \multicolumn{6}{|l|}{ Stanford binet } \\
\hline Primary and secondary & 33 & $97.86 \pm 10.8(77-118)$ & 44.84 & 11.3 & .02 \\
\hline High school & 34 & $99.78 \pm 8.3(80-120) \mathrm{I}$ & 48.44 & NA & NA \\
\hline University and over & 25 & $103 \pm 7.84(84-119)$ & 61.96 & NA & NA \\
\hline Total & 87 & NA & NA & NA & NA \\
\hline
\end{tabular}

Abbreviation: NA, not available. 
Ozmen A et al.

Table 6. Psychometric Test Points According to Family Income Level

\begin{tabular}{|lcccc}
\hline Psiychometric Test & Monthly Income & Number & Average Min-Maks & P \\
\hline Bayley Mental Development Scale & & & & \\
& $<1000$ & 6 & $89 \pm 4.1(81-97.2)$ & .241 \\
& $1000-1999$ & 25 & $91.9 \pm 7.4(76-106)$ \\
& $2000-2999$ & 11 & $94.8 \pm 10.9(70-115)$ \\
\hline Bayley Movement Development Scale & $>3000$ & 3 & $90 \pm 6.5(77-103)$ \\
\hline & Total & 45 & $92.1 \pm 8(76-108)$ \\
\hline Stanford Binet & & & \\
\hline & $<1000$ & 6 & $89.3 \pm 5(79-99)$ & .322 \\
\hline & $1000-1999$ & 25 & $92.9 \pm 8.6(75.9-110)$ \\
\hline & $2000-2999$ & 11 & $95.9 \pm 10.2(75-116)$ \\
\hline & $>3000$ & 3 & $89.2 \pm 9.4(69-108)$ \\
\hline & Total & 45 & $92.9 \pm 8.8(69-116)$ \\
\hline
\end{tabular}

Table 7. Psychometric Test Results According to Anemia Presence ${ }^{a}$

\begin{tabular}{lccc}
\hline & Ones With Anemia $(\mathbf{n}=\mathbf{2 1})$ & Ones Without Anemia $(\mathbf{n}=\mathbf{1 1 1})$ & $\mathbf{P}$ \\
\hline Borderline mental retardation & $2(9.5)$ & $1(0.9)$ & .003 \\
Dull normal & $4(19)$ & $6(5.4)$ & .015 \\
Normal & $13(61.9)$ & $98(88)$ & .04 \\
Bright normal & $2(9.5)$ & $6(5.4)$ & .54 \\
\hline
\end{tabular}

$\mathrm{a}_{\text {values are presented as No. (\%). }}$

Table 8. Denver Developmental Screening Test II Results of Patients ${ }^{\mathrm{a}}$

\begin{tabular}{lccc}
\hline & Abnormal & Suspicious & Normal \\
\hline Personal social development & $5(3.7)$ & $2(1.5)$ & $125(94.6)$ \\
Language development & $10(7.5)$ & $3(2.2)$ & $119(90)$ \\
Fine motor development & $5(3.7)$ & $1(0.7)$ & $126(95)$ \\
Gross motor development & $8(6)$ & $1(0.7)$ & $123(93)$ \\
\hline
\end{tabular}

$\mathrm{a}_{\text {values are presented as No. (\%). }}$

\section{Discussion}

Psychomotor development in children is under the effect of many factors including particularly genetic and environmental factors. In some of children with congenital heart disease, it has been shown that behavioral and neurological defects develop; their academic performances and intellectual functions are also undeveloped (7). The delay in neurodevelopment of patients has been tried to be explained with many causes such as more frequent occurrence of cerebral developmental problems in children with congenital heart disease than in normal population (2-4), negative effects of present cardiac disease on cerebral perfusion and oxygenation; hospitalization, frequent infection, and insufficient nourishment.

It was indicated in previous studies that academic problems, behavioral abnormalities and psychosocial issues in children with congenital cardiac disease are more frequently seen compared to those in society $(7,14,15)$. Nevertheless, these studies were carried out in children with 
complex congenital heart disease. The studies show that psychomotor development problems continued after correction operations in children with congenital heart disease (16-18). However, an important part of the studies in question was carried out in children with all congenital heart diseases without distinguishing patients $(16,17)$. In the study however, children with acyanotic congenital heart disease were evaluated in terms of their cognitive features in postoperative long term, in which increased neuropsychological problems were found compared with healthy children (18). Nonetheless, preoperative evaluations of patients were not made in the study by Sarrechia et al. In the present study, we evaluated psychomotor developmental condition of children with congenital heart disease in early period whose growth development was normal and who did not have heart failure and cyanosis. We showed that specific developmental disorders were more frequently seen than normal even in children with acyanotic simple congenital heart disease. We determined that intelligence level was below normal in 13 (10\%) patients and there was at least one specific developmental disorder in 33 (25\%) patients. Mental retardation rate in children was reported as 1 - $3 \%$ in studies carried out in Turkey (16) and it was determined at similar rate $(2 \%)$ in our study. However, dull intelligence condition (8\%) and specific developmental disorders (25\%) were determined at a higher level than in society. When specific developmental disorders were evaluated within itself, inattention and hyperactivity were seen in $3 \%$ of patients which was at a similar rate with society (17), nonetheless, learning difficulty was established in 10 (7.5\%) patients that was a higher level than throughout the society.

In an evaluation performed by DGTT II, no factor affecting gross and fine motor, language development and personal social development points was identified in children with acyanotic congenital heart disease.

When we evaluated the factors affecting mental development of children with acyanotic congenital heart disease; no relationship was identified among situations such as gender, period of gestation, mother milk intake period, formula use, initiation of additional nutrition on time, mothers' level of education and mental development of children with acyanotic congenital heart disease. Bayley mental development scale test points of children with acyanotic congenital heart disease under two years old were significantly lower in children who received an incubator care, had lower father education and anemia. StanfordBinet intelligence points of children with acyanotic congenital heart disease over two years old were determined significantly lower in children whose father education was limited and who had lower family income and anemia.

Receiving incubator care of children with acyanotic congenital heart disease in neonatal period has been identified to be a risk factor for the mental development delay in the first two years of age. Bayley Mental Development Scale evaluation average points ( $88 \pm 4.2$ ) of cases under two years old with incubator care were significantly lower than of those without incubator care $(93.17 \pm 8.5)(\mathrm{P}<0.05)$. The number of patients with incubator care was $32(24.2 \%)$ and the causes for staying in incubator were prematurity in 10 patients, respiratory distress in 11, indirect hyperbilirubinemia in 10 and hypoglicemia in 1 patient. This result supports that mental development is much more affected in perinatal period and early childhood.

Limited level of father's education was found to be linked with mental development retardation in children with acyanotic congenital heart disease both under and over two year olds. Mental development points displayed a significant increase when income level of families escalated in patients over two years old. The results obtained made us think that mental development in shildren with acyanotic congenital heart disease were under the effect of organic factors as perinatal period health issues and anemia and after the second year of life, however, socioeconomical factors improve the effects on mental development.

A significant relationship was found between anemia and low intelligence scores in all age groups. Anemia was determined in 21 (15.9\%) patients in the study. All anemias were iron deficiency anemias. Although this patient group was under close follow-up, iron deficiency anemia was encountered quite frequently. Iron is found in high quantity in oligodendrocytes in a developing brain (18). Iron deficiency is known to affect glial cell development and energy metabolism negatively and iron deficiency anemia is reported to cause deceleration in neurocognitive functions (19-22). Iron treatment has been revealed to ameliorate the viscosity symptoms of iron treatment in cyanotic and complex congenital heart disease and effort capacity of patients $(23,24)$. Iron deficiency and iron deficiency anemia in acyanotic congenital heart disease patients increase heart failure findings and affect clinical picture negatively. We showed in our study that in addition to known effects of iron deficiency; it affects mental development of children with acyanotic cardiac disease in a negative way. The results that we attained put forward the importance of early diagnosis and treatment of iron deficiency and anemia once more.

As a result, socioeconomical difficulties, perinatal period health issues and iron deficiency anemia are most influential factors in neurodevelopment of children with acyanotic congenital heart disease.

\section{References}

1. Boneva RS, Botto LD, Moore CA, Yang Q, Correa A, Erickson JD. Mortality associated with congenital heart defects in the United States: trends and racial disparities, 1979-1997. Circulation. 2001;103(19):2376-81. [PubMed: 11352887]

2. Limperopoulos C, Majnemer A, Shevell MI, Rosenblatt B, Rohlicek C, Tchervenkov C. Neurodevelopmental status of newborns and infants with congenital heart defects before and after open heart surgery. J Pediatr. 2000;137(5):638-45. doi:10.1067| mpd.2000.109152. [PubMed:11060529]

3. Limperopoulos C, Majnemer A, Shevell MI, Rosenblatt B, Rohlicek C, Tchervenkov C. Neurologic status of newborns with congenital heart defects before open heart surgery. Pediatrics. 1999;103(2):402-8. [PubMed: 9925832] 
4. LichtDJ, Shera DM, Clancy RR, Wernovsky G, Montenegro LM, Nicolson SC, et al. Brain maturation is delayed in infants with complex congenital heart defects. J Thorac Cardiovasc Surg. 2009;137(3):52936. doi:10.1016/j.jtcvs.2008.10.025. [PubMed:19258059]

5. Donofrio MT, Massaro AN. Impact of congenital heart disease on brain development and neurodevelopmental outcome. Int J Pediatr. 2010;2010. doi: 10.1155/2010/359390. [PubMed: 20862365]

6. Newburger JW, Bellinger DC. Brain injury in congenital heart disease. Circulation. 2006;113(2):183-5. doi: 10.1161/CIRCULATIONAHA.105.594804. [PubMed:16418448]

7. Marino BS, Lipkin PH, Newburger JW, Peacock G, Gerdes M, Gaynor JW, et al. Neurodevelopmental outcomes in children with congenital heart disease: evaluation and management: a scientific statement from the American Heart Association. Circulation. 2012;126(9):1143-72. doi: 10.1161/CIR.0b013e318265ee8a. [PubMed: 22851541]

8. Bayley N. Bayley Scales of Infant Development. 2nd ed. The Psychological Corporation; $1993 .$.

9. Guedes DZ, Primi R, Kopelman BI. BINS validation - Bayley neurodevelopmental screener in Brazilian preterm children under risk conditions. Infant Behav Dev. 2011;34(1):126-35. doi: 10.1016/j. infbeh.2010.11.001. [PubMed: 21185605]

10. Terman LM, Merrill MA. Stanford-Binet intelligence scale: Manual for the third revision, form IM. 1960.

11. Aktas D, Utine EG, Mrasek K, Weise A, von Eggeling F, Yalaz K, et al. Derivative chromosome 1 and GLUT1 deficiency syndrome in a sibling pair. Mol Cytogenet. 2010;3(1):10. doi:10.1186/1755-8166-3-10. [PubMed: 20509907]

12. Anlar B, Yalaz K. Denver II Developmental screening test, its adaptation to turkish children and standardization. Ankara: HUMF Ped. Neurology Department; 1995. pp. 1-43.

13. Tunc B. Iron deficiency anemia in children. TURK Child Hosp J. 2008;2(2):43-57.

14. Utens EM, Verhulst FC, Meijboom FJ, Duivenvoorden HJ, Erdman RA, Bos E, et al. Behavioural and emotional problems in children and adolescents with congenital heart disease. Psychol Med. 1993;23(2):415-24. [PubMed: 8332658]

15. Bellinger DC, Newburger JW. Neuropsychological, psychosocial, and quality-of-life outcomes in children and adolescents with congenital heart disease. Prog Pediatr Cardiol. 2010;29(2):87-92.

16. Dogangun B. Psyhchiatric conditions requiring private education. I.U. Cerrahpasa medicine faculty continuing education events most encountered psychiatric diseases symposium series. 2008:157-74..

17. Aydin H, Diler RS, Yurdagul E, Oguz S. Attention deficit hyperactivity disorder Rate in Parents of Children Diagnosed with attention deficit hyperactivity disorder. Klin Psikiyatr Derg. 2006:70-4.

18. McCann JC, Ames BN. An overview of evidence for a causal relation between iron deficiency during development and deficits in cognitive or behavioral function. Am J Clin Nutr. 2007;85(4):93145. [PubMed:17413089]

19. Beard JL, Wiesinger JA, Connor JR. Pre- and postweaning iron deficiency alters myelination in Sprague-Dawley rats. Dev Neurosci. 2003;25(5):308-15. doi: 10.1159/000073507. [PubMed: 14614257]

20. Youdim MB, Yehuda S. The neurochemical basis of cognitive deficits induced by brain iron deficiency: involvement of dopamineopiate system. Cell Mol Biol (Noisy-le-grand). 2000;46(3):491-500. [PubMed:10872737]

21. Beard JL, Felt B, Schallert T, Burhans M, Connor JR, Georgieff MK. Moderate iron deficiency in infancy: biology and behavior in young rats. Behav Brain Res. 2006;170(2):224-32. doi: 10.1016/j. bbr.2006.02.024. [PubMed:16569441]

22. Tunaoglu FS, Gursel T, Bozkurt A, et al. The effect of iron deficiency on platelet 5-hydroxytryptamine levels and relation to behavioral abnormalities. Acta Pediatr. 1991;(7):35-7.

23. Broberg CS, Bax BE, Okonko DO, Rampling MW, Bayne S, Harries $\mathrm{C}$, et al. Blood viscosity and its relationship to iron deficiency, symptoms, and exercise capacity in adults with cyanotic congenital heart disease. J Am Coll Cardiol. 2006;48(2):356-65. doi: 10.1016/j.jacc.2006.03.040. [PubMed:16843187]

24. Tay EL, Peset A, Papaphylactou M, Inuzuka R, Alonso-Gonzalez R, Giannakoulas G, et al. Replacement therapy for iron deficiency improves exercise capacity and quality of life in patients with cyanotic congenital heart disease and/or the Eisenmenger syndrome. Int J Cardiol. 2011;151(3):307-12. doi: 10.1016/j. ijcard.2010.05.066. [PubMed: 20580108] 